\title{
Collaborative Learning 2.0: \\ Open Educational Resources
}

Alexandra Okada

The Open University, UK

Teresa Connolly

The Open University, UK

Peter J. Scott

The Open University, UK

A volume in the Advances in Higher Education and Professional Development (AHEPD) Book Series

Information Science
REFERENCE

An Imprint of IGI Global 
Managing Director:

Senior Editorial Director:

Book Production Manager:

Development Manager:

Development Editor:

Acquisitions Editor:

Typesetter:

Cover Design:
Lindsay Johnston

Heather A. Probst

Sean Woznicki

Joel Gamon

Myla Harty

Erika Gallagher

Russell A. Spangler

Nick Newcomer, Lisandro Gonzalez

Published in the United States of America by

Information Science Reference (an imprint of IGI Global)

701 E. Chocolate Avenue

Hershey PA 17033

Tel: 717-533-8845

Fax: 717-533-8661

E-mail: cust@igi-global.com

Web site: http://www.igi-global.com

Copyright ( 2012 by IGI Global. All rights reserved. No part of this publication may be reproduced, stored or distributed in any form or by any means, electronic or mechanical, including photocopying, without written permission from the publisher. Product or company names used in this set are for identification purposes only. Inclusion of the names of the products or companies does not indicate a claim of ownership by IGI Global of the trademark or registered trademark.

\section{Library of Congress Cataloging-in-Publication Data}

Collaborative learning 2.0 : open educational resources / Alexandra Lilavati Pereira Okada, Teresa Connolly, and Peter J. Scott, editors.

p. cm.

Includes bibliographical references and index.

Summary: "This book offers a collection of the latest research, trends, future developments, and case studies pertaining to collaborative learning"--Provided by publisher.

ISBN 978-1-4666-0300-4 (hardcover) -- ISBN 978-1-4666-0301-1 (ebook) -- ISBN 978-1-4666-0302-8 (print \& perpetual access) 1. Group work in education. 2. Internet in education. 3. Open learning. I. Okada, Alexandra. II. Connolly, Teresa, 1960- III. Scott, Peter J.

LB1032.C563 2012

371.39'5--dc23

2011052549

This book is published in the IGI Global book series Advances in Higher Education and Professional Development (AHEPD) (ISSN: 2327-6983; eISSN: 2327-6991)

British Cataloguing in Publication Data

A Cataloguing in Publication record for this book is available from the British Library.

All work contributed to this book is new, previously-unpublished material. The views expressed in this book are those of the authors, but not necessarily of the publisher. 


\title{
Chapter 10 \\ Managing Assessment Resources in the Open ICOPER Content Space
}

\author{
Israel Gutiérrez Rojas \\ Universidad Carlos III de Madrid, Spain \\ Raquel M. Crespo \\ Universidad Carlos III de Madrid, Spain \\ Michael Totschnig \\ Wirtschaftsuniversität Wien, Austria \\ Derick Leony \\ Universidad Carlos III de Madrid, Spain \\ Carlos Delgado Kloos \\ Universidad Carlos III de Madrid, Spain
}

\begin{abstract}
With the introduction of the Web 2.0 philosophy in the learning arena, the way learning actors interact has changed substantially. From a collaborative perspective, all the actors in the learning landscape could make use of a variety of tools for collaboration, making up what it is called: "collaborative learning 2.0." In this chapter, the discussion is focused on the open educational resources (OER), concretely open assessment resources, i.e., open resources used in the assessment process (formative and/or summative). The authors explore the way to create, share, search, manage, and access to these resources; all these actions are described from the context of collaboration inherited from the Web 2.0 paradigms: collaboration among teachers and course designers, teachers and learners, and any other factors that could arise in the assessment process. On the other hand, the approach to managing the open assessment resources is based on an outcome-based assessment process because of the great importance of the outcome-based learning.
\end{abstract}

DOI: $10.4018 / 978-1-4666-0300-4 . c h 010$

Copyright $\odot$ 2012, IGI Global. Copying or distributing in print or electronic forms without written permission of IGI Global is prohibited. 


\section{INTRODUCTION}

The usage of a repository of assessment resources matches up with the collaboration Web 2.0 philosophy. Several teachers from several institutions can author assessment resources collaboratively, improve not-up-to-date material, share it with the community, provide comments about the usage of some resources like the learners performance or peer review other's resources: the possibilities are almost infinite. On the other hand, learners could also drive their own learning using self-assessment resources or providing feedback of their experience with some resources. Therefore, here we are presenting an eminently collaborative tool.

Sharing assessment resources among teachers and course developers is a feature that has a great potential. The exposition in this article tries to shed some light over this feature and provides a solution by means of an application prototype. The learning management systems (LMSs) are the entry point for the mentioned stakeholders to the educational resources used by an institution. A possible solution for sharing assessment resources among LMSs would be to use an information repository, such as the Open ICOPER Content Space (henceforth referred to as OICS). By doing so, assessment content and information could be centralized and the material would be accessible from any other platform. All contents could be downloaded from a single centralized site, thus simplifying the integration of different LMS and interoperability.

The repositories of educational resources enhance some e-learning processes like the collaborative authoring of resources by several teachers, the communication between teachers and learners and the enrichment of educational resources by means of annotations (teacher reflections, learner feedback, peer review comments).

The Open ICOPER Content Space (OICS) is an open repository of educational resources that permits teachers and learners create, share, enrich and reuse any kind of learning materials.
The educational resources the OICS manages range from instructional design resources (e.g. learning designs, teaching methods and assessment methods), learning outcome definitions, learner assessment resources to learner's achieved learning outcomes.

As the Bologna process has led to the reproduction of several learning programs in many European institutions, the objective of this tool is supporting content authors in this endeavour. Due to the learner assessment is a key process and it has to focus on learning outcomes, the utility of this tool for course developers is unquestionable.

The objectives of this article are:

- Show the importance of the outcome-based assessment process

- How an Open Educational Repository could support teachers and course developers in the planning and design of the outcome-based assessment

- Introduce an actual implementation of these concepts in the .LRN platform

\section{BACKGROUND}

\section{Outcome-Based Assessment Concepts}

There are two main concepts in any learning scenario: the learning outcomes that are intended to be achieved by the learner and the learning designs as the means by which those can be achieved. In order to complete the picture, learner assessment appears as the process of testing the achievement of learning outcomes (knowledge, skills and/or competences) by an individual learner and providing the corresponding information reporting about the learner achievements and/or potential indications for improving them (Crespo et al., 2010). Learner assessment is thus the binding process by which the intended learning outcomes defined by a learning design are accredited as actual learn- 
Figure 1. Learner assessment concept map

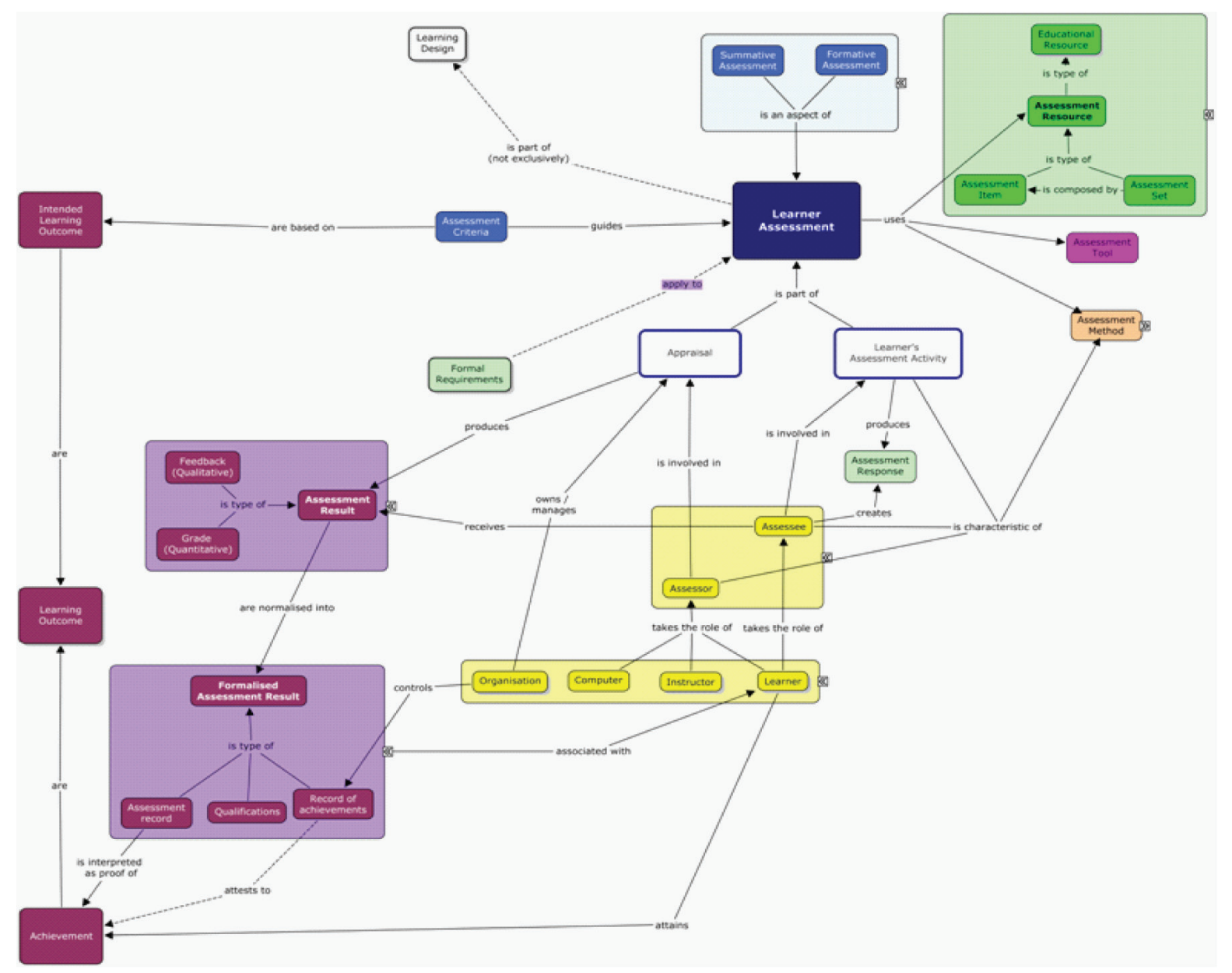

ing outcomes acquired by a learner, transforming those learning outcomes from potential to factual.

Two representative cases can thus be considered (Bloom et al., 1971). On the one hand, a learning design which includes a final assessment process to check whether the learners have successfully accomplished the intended outcomes. That is, a summative assessment, which provides a measure of achievement or failure, made in respect of a learner's performance in relation to the intended learning outcomes of the program of study (QAA, 2010). The learner assessment concept (Figure 1) would comprise the whole process, including in this case both the activity of the learners taking the exam as well as the appraisal phase when the instructor gauges the learners' responses and awards them the corresponding grades.

On the other hand, a learner assessment process can be a learning activity itself, aiming to provide formative feedback to the learner about his/her performance and support their progress (Yorke, 2003). An example of this case is a peer review activity integrated as part of the learning design. The learner assessment can again be subdivided into two sub-processes: the development of the project by the learner (learner's activity) and the reviewing (appraisal).

Further analysis of the relationship among learning outcomes, learning design and learner assessment requires the introduction of the key 
concepts related to the latter: assessment resource, roles (assessor and assessee), assessment results, etc. Figure 1 represents these key concepts as well as the relationships interconnecting them.

In a similar way that a learning design uses learning resources for supporting the learning process, an assessment process also makes use of specific resources. An assessment resource is a special type of learning resources, which is used for assessment purposes and it involves interaction with the learner. Assessment resources should include additional information besides the textual instructions provided to the learners.

Two roles are involved in the assessment process: the assessor (responsible of the appraisal) and the assessee (whose learning outcomes are appraised). They typically correspond to the learning supporter and the learner roles defined for the unit of learning, respectively. As a product of the appraisal done by the assessor, the assessment results are generated, consisting of information about the performance of the assessee, his/her achievement of the learning outcomes and/or formative feedback for supporting the learner's progress. Usually, assessment results can correspond to specific learning outcomes and may need further post-processing to inform about more generic learning outcomes.

The assessment record acts as the binding between the learning outcomes that the learner can actually claim and the assessment process (when successfully completed). In order to be trusted and to provide complete information, assessment records should include data about the type of assessment performed as well as the responsible expert and institution that endorses this evaluation (the assessing body).

Finally, the description of the assessment process is formalized into the assessment method concept, which comprises the characteristics defining a certain assessment process (such as who plays the role of assessor, the type of activity posed to the assessee, the purpose of the process, the kind of results to be provided, etc.). The assessment method is strongly influenced by the assessed learning outcomes. Different types of learning outcomes require different assessment methods. Different assessment methods can also be defined depending on the actors playing such roles. The assessor role can be played by the student him/herself, peer learners, the instructor or automatic assessment. Regarding the assessee role, learners can be assessed individually or in groups (collaboratively). Again, the learning outcomes can be determinant in the selection.

The assessment method is thus a concept that can be related to the teaching method defined for the learning design, as it plays an equivalent role for the learner assessment (namely, the generic description of the process) and can thus be considered an integral component of the teaching method. So the teaching method includes references to the assessment method(s) to be applied when learner assessment activities are included.

Figure 2 shows the conceptual map for the proposed learning outcome based assessment model, abstracting the detailed concepts and focusing on interconnecting key ones.

In summary, learning outcomes and assessment are connected in various ways:

- At design time: learner assessments are designed to evaluate the attainment of certain intended learning outcomes.

- At runtime: learner assessments provide information about actual learning outcomes achieved by a learner; the assessment results are normalized into assessment records.

- At post-runtime: the learner's outcome profile is updated with the gained learning outcomes, i.e., the achievements he/ she has obtained; these achievements are evidenced by the normalized assessment records, results of the assessment process. 
Figure 2. Learner assessment summarized concept map

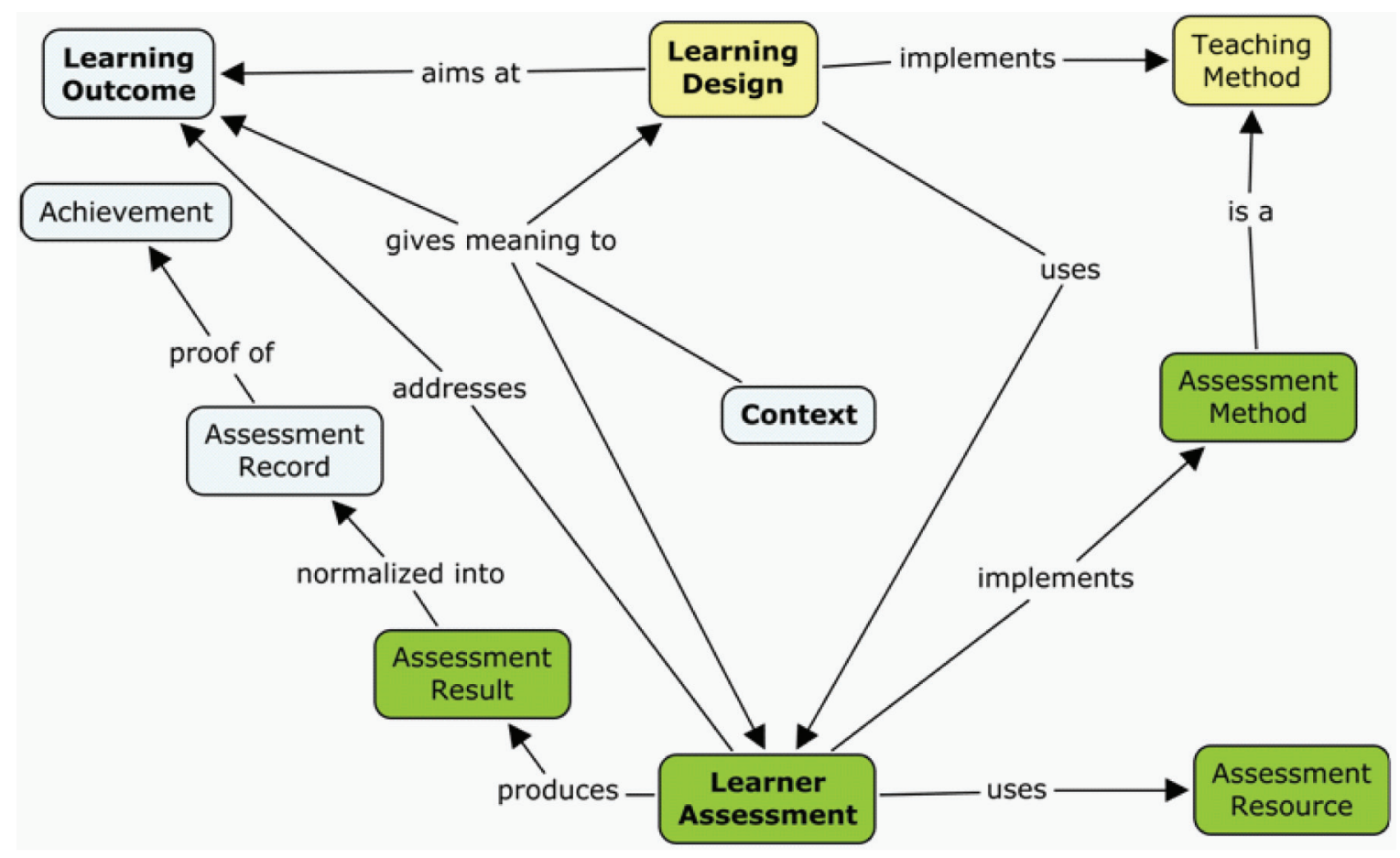

\section{Relevant Standards and Specifications for Open Assessment Resources}

In this section, the most relevant standards and specifications related to the authoring and management of open assessment resources are introduced. The presented standards and specifications used in the assessment process can be classified in two types: inherent of the assessment process (e.g., IMS QTI for representing assessment resources) and supporting the assessment process, i.e., assessment and specifications used in the e-learning contexts but not specific of the assessment process.

\section{IMS QTI}

The IMS Question and Test Interoperability format (IMS QTI, 2010) defines a specification for assessment resources and results, allowing the exchange of such material among authoring tools, delivery systems, content repositories and LMSs. It is still a specification, because it has not yet been backed by any standardization body. Nevertheless, it has become very popular and considered nowadays a standard de facto for assessment resources.

The specification consists of a data model defining the structure of the questions, the tests, feedback and results. An XML binding is provided, which is the most commonly used, that facilitates the exchange of the materials.

There are several IMS QTI versions, among them versions 1.2.1 and 2.1 stand out. IMS QTI 1.2.1 was released in 2002 and it is the most popular, used in learning systems (Agea et al., 2009) and endorsed by the IMS Global Learning Consortium. The IMS QTI data model in its 1.2.1 version relies in the following core elements:

- Item: contains a question, its presentation or rendering instructions, the response processing applied to the obtained responses and the feedback, and the meta-data describing the item 
Figure 3. Learner assessment data level

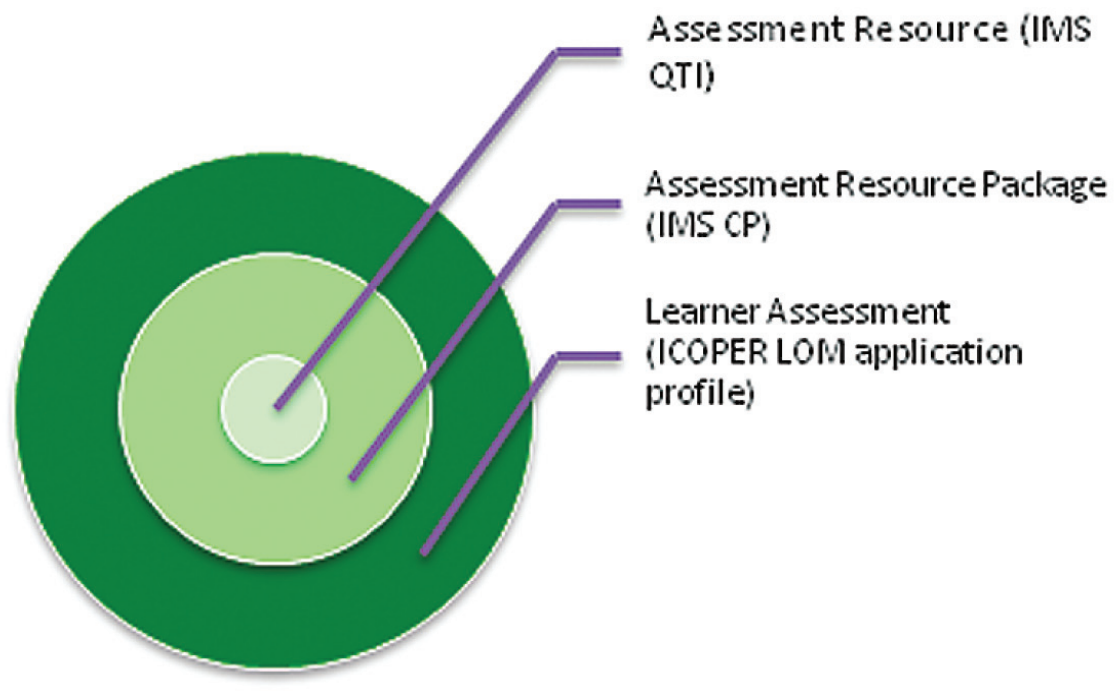

- Assessment: contains a collection of items used to determine a level of mastery. It contains instructions to enable different sequences of items and the corresponding scoring instructions.

- Section: contains groups of items to support complex schemes of scoring as well as sequencing.

- Object bank: a collection of items and sections. Its content is searchable.

Version 2 of the specification proposed a significant review of the four basic objects in version 1.2.1. The first revision, version 2.0, tackled the review of the first of these objects, the item. The simplification has been significant, but unfortunately, the corresponding tasks for the rest of objects have not been achieved. Version 2.1 is still in draft status. As a consequence, the overall simplification and refinement of the specification to be achieved in version 2 is right now incomplete, and the only complete (and endorsed by IMS) specification is version 1.2.1.

In order to realize the exchange of assessment resources in a federated repository, a common assessment specification must be used. Although
IMS QTI 1.2.1 presents deficiencies and limitations, as discussed in (Gutiérrez Rojas et al., 2009) and (Agea et al., 2010), it is nevertheless considered a de facto standard by the industry. Thus, this is the specification selected in order to widen the scope of the repository, accomplish universal access and allow it to provide services for both authoring tools as well as LMSs.

\section{ICOPER LOM Application Profile}

The solution for defining learner assessments, that is, the assessment resources enriched with other related information, such as intended learning outcomes or assessment methods, was presented in (Gutiérrez Rojas et al., 2010). The solution was based on the integration of the IMS QTI files with the ICOPER LOM application profile (AP) as shown in Figure 3. The assessment resource described using IMS QTI is optionally packaged by means of IMS Content Package (CP) and then the ICOPER LOM AP layer is attached.

The ICOPER LOM AP is an IEEE LOM profile defined in the context of the ICOPER project to describe the outcome-related information of learning objects of several types, e.g., learning 
designs, learner assessments, teaching methods, etc. The main concepts of learner assessment are mapped into IEEE LOM profile as follows:

- $\quad$ Learning resources are presented as IMS QTI 1.2.1 files.

- $\quad$ Learner assessment is defined by all LOM attributes and categories (LOM Learning Resource Type: "Learner Assessment").

- Annotations of the resources can be given, using the IEEE LOM Annotation.

- Assessment methods are related to learner assessment using IEEE LOM Relation and several assessment methods can be defined for a resource.

- The intended learning outcomes of the assessment resource are defined in an IEEE LOM extension included in the ICOPER AP. More information can be obtained from (Agea et al., 2010).

- Learning designs are related to the learner assessment through IEEE LOM Relation.

\section{PALO}

The Personal Achieved Learning Outcomes (PALO) data model (Najjar et al., 2010) is a simple schema proposed to capture information on learning outcomes (knowledge, skills and competences) achieved by a learner and relations among those outcomes. Information on the context where the learning outcomes are obtained or applied, assessment records and levels (e.g. proficiency level) associated to the outcomes are also part of this schema.

One of the main challenges of communities and systems that deal with learning outcome information is interoperability. Different communities and systems may use different data models to represent information on skills, knowledge or competence obtained by a person that is required for a job or a task.

The PALO specification is a step towards a common model supporting the exchange of such data, to enhance interoperability of personal learning outcome information between, for example, learning management systems, e-portfolios, social applications and recruitment systems.

This data model enables describing relations between learning outcomes of learners, in addition to contextual and evidence related information. The PALO schema should enable capturing the following:

- relations between achieved learning outcomes, regardless of the taxonomies or ontologies they belong to;

- contextual information on where the achieved learning outcome is obtained or applied;

- information about all types of evidence and assessment that prove the achievement of a learning outcome;

- information about levels and ranking of an achieved learning outcome, like proficiency level.

\section{THE OPEN ICOPER CONTENT SPACE}

In the context of the ICOPER project, the Open ICOPER Content Space(OICS) has been designed as a platform offering services for the management of shareable educational resources as part of outcome-oriented learning processes. Its backend consists in two synchronized repository servers capable of storing resources and metadata, and offering specialized services for publication, search and retrieval. The OICS repositories store:

- learning outcome definitions capturing the key characteristics of a learning outcome, independently of its use in any particular context or target group;

- a critical mass of learning content harvested from content providers through the OAI-PMH protocol; 
- $\quad$ teaching and assessment methods and

- $\quad$ learning designs that can be published directly from desktop authoring applications or uploaded through a web user interface;

- personal achievement profiles controlled by users and accessible through learning management system or social network applications;

- $\quad$ learning opportunities announced by universities or course delivery platforms.

The repositories are consumers of a set of services improving the quality of the metadata. These services are explained in more detail in Klerkx et al. (2010).

- The registry service provides a catalogue of up-to-date information about learning object repositories (LORs) and allows the harvester instance used for the OICS to retrieve information about the OAI-PMH endpoint.

- The validation service ensures that only metadata records are stored which comply with the ICOPER LOM Application Profile, which is based on IEEE Learning Object Metadata (LOM).

- The transformation service allows applying mappings between foreign vocabularies to ICOPER specific ones.

- The identifier service generates unique and persistent identifiers that are added to metadata records upon ingestion into the OICS. Resolution to multiple views of the resource is provided through a simple web service.

The services the OICS provides to client applications have been bundled into a coherent API, the OICS Middle Layer (Figure 4). Its key focus is the integration of concepts and data related to the key processes in outcome-based education. The OICS middle layer provides services for search and retrieval of learning resources, for publica- tion, for the management of users and groups and for the management of learning outcome profiles within these key processes (Totschnig etal., 2010).

\section{Search and Retrieval}

The search and retrieval service gives access to the OICS resources by providing specific access methods for the different types of objects (learning outcome definitions, teaching methods, learning designs and learner assessments). Three example bindings for this service have been implemented:

- $\quad$ The ATOM binding exposes all resources as ATOM feeds that can be filtered based on values in the LOM metadata.

- The JSON binding uses a REST interface and provides the results to the client tools in the JavaScript Object Notation data for-

Figure 4. OICS middle layer

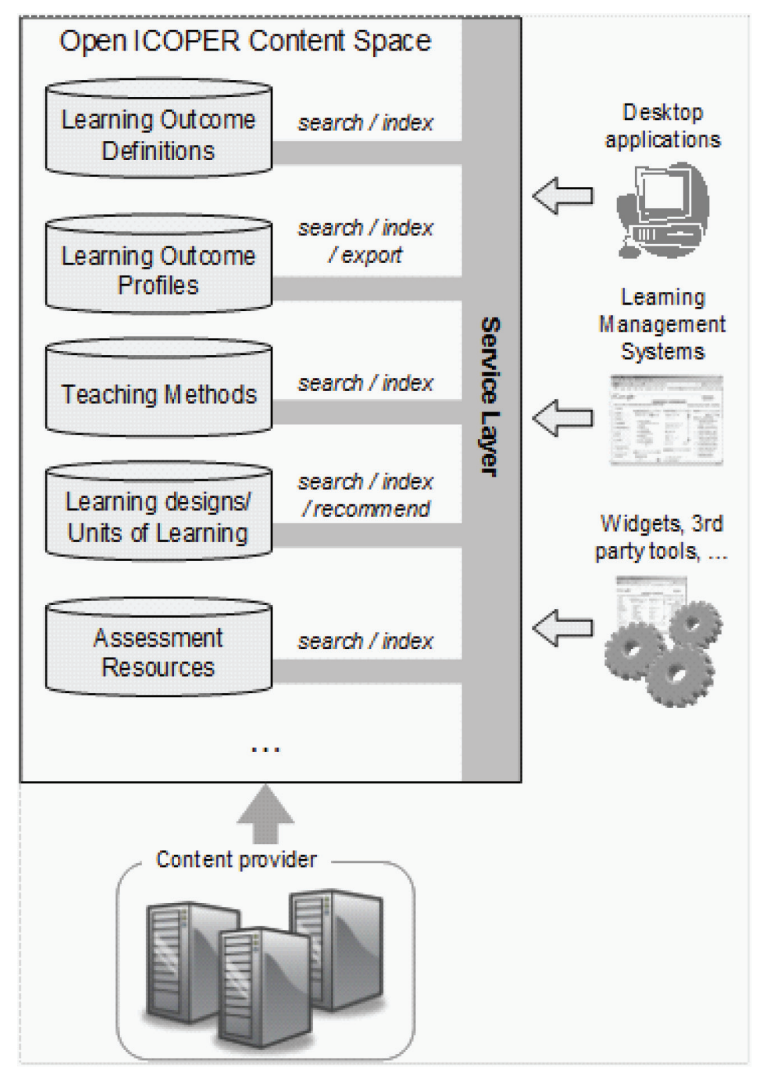


mat. JSON is a lightweight data format heavily used by web developers due to its simplicity (e.g. native evaluation of results in JavaScript) compared to the traditional XML data format approaches, which often require cumbersome DOM-based processing.

- A PHP search script forwards PLQL expressions to the SQI SOAP end point provided by the KUL repository.

\section{Publication}

The OICS implements the Sword/AtomPub binding of the SPI specification, learning objects and metadata records can be published to collections. Extending the SPI specification, The OICS implementation allows updating and retrieving of parts of the metadata record thus making it very easy to query and manipulate individual metadata fields relevant in specific use cases.

\section{Learning Outcome Profiles}

Users of the OICS can manage their learning outcome profile according to the Personal Achieved Learning Outcomes (PALO) data model both through a web UI and the same publication service as used for publishing learning resources.

\section{Other Initiatives of Open Assessment Resources}

There have been some initiatives for creating Open Educational Resources (OER) repositories, like the JISC OER program (JISC OER, 2010), which purpose is "make a significant amount of existing learning resources freely available online, licensed in such away to enable them to be used and repurposed worldwide." Some of these repositories contain assessment resources in several formats (e.g., IMS QTI), like Fetlar (Fetlar project, 2010) that collect maths assessment using IMS QTI and
Bioscience UKOER project, whose resources can be accessed through JorumOpen (JorumOpen, 2010).

\section{MANAGING OUTCOME-BASED OPEN ASSESSMENT RESOURCES IN A FEDERATED REPOSITORY}

In the context of the ICOPER project (ICOPER, 2010), we have developed a prototype as a proof of concept of these hypotheses. It is called "outcomebased assessment resources management tool" and it is integrated in the .LRN learning management system (LMS).

\section{Usage of Standards and Specifications}

From a technological perspective, one of the main challenges we have confronted is the assessment resources interoperability. The IMS QTI specification is supposed to solve this problem but the actual implementation in the assessment tools suffer from lack of interoperability (Agea et al., 2010). In this sense, it is worth pointing out the IMS Common Cartridge (IMS CC, 2010).

The IMS CC is a set of open standards that, if followed by content developers and learning platforms, enable strict interoperability between content and systems. Among other things, it specifies a standard for test items, tests, and assessments. This standard allows learning systems to understand imported assessments so they can be manipulated as needed in the learning system.

The IMS CC 1.0 provides an IMS QTI 1.2.1 profile oriented to interoperability of questions and tests. Besides, it covers all the main features and question types used in the current QTI implementations.

The Common Cartridge supports profiles of the following question types:

- Multiple Choice (Single Response)

- Multiple Choice (Multiple Response)

- True/False 
- $\quad$ Essay

- Simple Fill in the Blank: single response box with single correct answer that is processed as an exact match

- Pattern Match: single response box with multiple potential answers that support exact match, containment matching and regular expression matching

The profiles for each of these question types describe how they support:

- Feedback

- Hints

- Sample solutions

- $\quad$ Relative scoring

In addition, questions support a number of metadata attributes that describe:

- A suggested weighting for the question in the assessment

- A category for the question.

So, the interoperability of the tools that implement this profile is guaranteed, and they could make use of all the resources in the repository and manage them in a proper way.

Once defined the specification to be used for assessment resources, it is necessary to indicate which non-specific assessment formats were used together with IMS QTI. The ICOPER LOM AP was selected for enriching the assessment resources with information about:

- Intended learning outcomes: selected from a repository of learning outcome definitions in the OICS, collected from several Higher Education Institutions (HEI).

- Assessment methods: selected from a repository of assessment methods in the OICS collected in a theoretical basis.
- Annotations about the resources: there are three types of annotations, i.e., annotation resulted from a peer review of the resources, teacher reflections and student feedback.

Finally, PALO was used to represent the assessment records, i.e., the result of normalizing the summative assessment results, the achievements and the learner's profile, composed by achievements evidenced by assessment records.

\section{Open Assessment Resources Use Cases}

The stakeholders of this tool are teachers and course developers, and it covers the following use cases:

- Outcome-based search of assessment resources in the OICS

- Publication of assessment resources in the OICS

- Annotation of assessment resources with teachers and learners reflections

- Updating of learner's personal achieved learning outcomes (PALO)

University Carlos III of Madrid (UC3M) has developed a prototype integrated into the .LRN platform that demonstrates various use cases related to the learner assessment process:

\section{(1) Outcome-Based Search of Assessment Resources}

Once defined assessment method and learning outcomes of a course, the instructional designer should find appropriate assessment resources aligned to them, and this process is enabled by the .LRN module. The designer is able to search for assessment resources in the OICS by keyword, but he/she is also able to filter the results by the intended learning outcomes of the course (avail- 
able in the learning outcome definitions repository) and by the assessment method he decided to use to orchestrate the resources.

The described use case makes use of the search service of the middle layer API of the OICS in order to search assessment resources from several repositories. This service also provides means for the filtering process by learning outcomes and/or assessment method.

\section{(2) Sharing Annotations about Assessment Resources}

Once an activity involving a published assessment resource has finished, teachers can make use of the annotation system in order to provide information about the students' performance. Teachers could also collect students' feedback to annotate the assessment resource with. This information enriches the published resource for potential instructional designers willing to re-use it.

This sharing annotation system uses some services of the OICS via the middle layer API. Firstly, the publication service is used to publish the resources and their LOM metadata in the OICS. Secondly, the service that allows updating the metadata record of a resource is used to update it with annotation information.

\section{(3) Learning Outcomes: Achievements}

After the completion of the course, and therefore the assessment activities, it is time for teachers to officially close the course. The implemented application provides the teacher with an interface to facilitate this task. It shows a list of the students of the course and the assessment result (grade) of each assessment activity carried out in the course. There is also a final grade automatically calculated as the arithmetic mean of all the results, but the teacher can modify it taking into account other factors. The teacher can also provide some textual feedback for any student's final grade.
Once the teacher has finished this task, he can officially close the course. The results of this action is that the profiles of all the students passing the course (in this case it means a final grade of 5 or more because the prototype uses a grading scale 0 to 10 , proper to the Spanish system) will be updated with the achievements of the course, that is, the learning outcomes achieved. These achievements are also evidenced by an assessment record, which is an official record corresponding to the final grade of the course and has the University as the assessing body.

This process uses the service of the OICS middle layer that allows updating the learner's profile with assessment records and achievements.

A screenshot of the developed prototype for managing open assessment resources in the Open ICOPER Content Space is shown in Figure 5.

\section{Evaluation of the Proposal}

The .LRN prototype evaluation, according to the methodology defined in ICOPER, targets three types of audience (stakeholders):

- Engineering evaluation targeted to implementers, tool developers and technology providers.

- End-user evaluation targeted to instructors, learners, curriculum developers, administration or management.

- Epistemological evaluation targeted to researchers and standardization bodies.

The first one consists of a survey about the prototype implementation and the middle layer API. It will provide the perspective of these stakeholders from a technical point of view.

In the .LRN prototype, the end-user evaluation targets faculty members and course developers. The end user evaluation of the .LRN prototype has been conducted in two events:

1. A workshop organised in the eMadrid conference at University Carlos III of Madrid, where 13 
Figure 5. .LRN prototype screen capture

. $\mathrm{RN}$

Home : ICOPER Assessment

Home | Classes | Communities | Control Panel $\mid$ Administration
Learning Outcome based Asessment search for "java"

Search results: 12

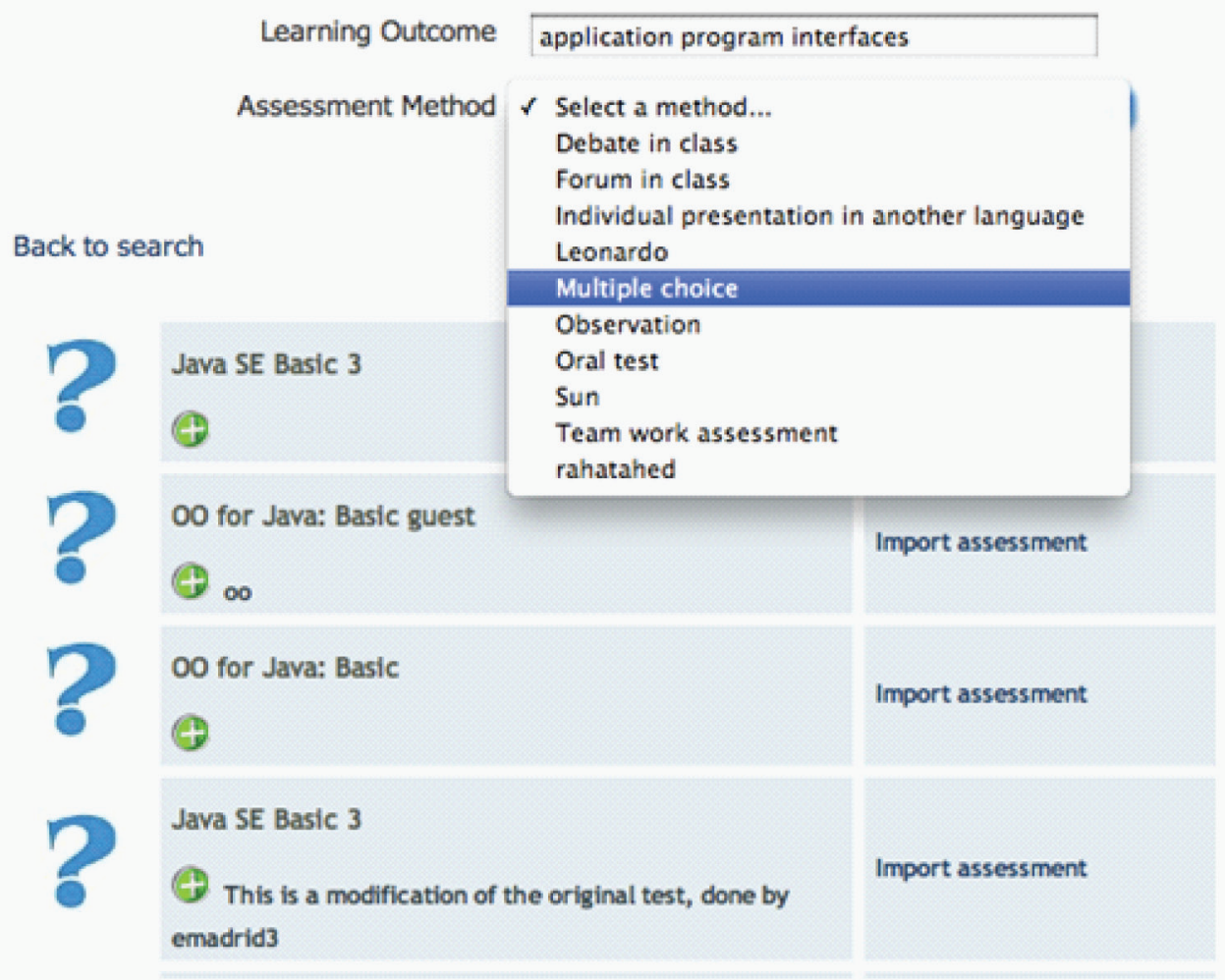

user evaluations were collected. The evaluation consisted of brief theoretical introduction followed by a demo of the prototype. Then, the participants had the opportunity to use the prototype by themselves to carry out a set of predefined tasks and ended up with a survey about their experience with the tool.

2. A series of personal interviews (5) were conducted in the University Carlos III of Madrid (2) and University of Cyprus (3). The objective of these interviews was to obtain quantitative evaluation data of the prototype. The profile of the interviewees was course developers and faculty members: 4 males and 1 female aged between 25-39, all teachers of IT related subjects. The interviews were recorded and the highlights summarised afterwards in order to let the interviewees freedom to explain themselves, according to the defined methodology.

From the overall quantitative analysis it can be concluded that the faculty members and course developers are satisfied with the implemented prototype. They rated great the learnability of the tool and the standard support (although this value is 
not very significant due to some users did not have a great knowledge about e-learning standards).

Both the quantitative and qualitative results have been used as empirical evidence for a set of recommendations, described below. These recommendations are addressed to standardization bodies and technology providers.

1. Usage of IMS QTI profile defined in the IMS CC in assessment tools

2. Hide assessment specifications complexity to end users in assessment tools

3. Provide teachers tools for formative assessment integrated in assessment tools

4. Relate assessment resources to intended learning outcomes

5. Support annotation of assessment resources in assessment tools

6. Implementation of integrated environments for outcome-based assessment based on the previously described standards and specifications

\section{FUTURE RESEARCH DIRECTIONS}

Related to the previously defined recommendations, we are also working on defining a set of recommendations for faculty members and higher education management. Therefore, it is possible that more evaluation events were necessary to get more empirical evidence.

On the other hand, a set of new functionalities good to have in the implemented prototype is the following:

- $\quad$ Add the possibility to define new assessment methods in the OICS, to be used to annotate the resources

- Integrate new repositories of assessment resources in several languages in the OICS

- Define a clear process to reference the reused open resources
Finally, it is worth mentioning that a research topic very related to this work is to define a standards and specifications for assessment resources able to evaluate skills and competences. The set of learning outcomes assessment by resources defined in IMS QTI (basically questions and tests) are knowledge outcomes and some skills. But it exists the need of assessing high level skills in the current HEI and companies, and the used resources should be expressed in a standardized way.

\section{CONCLUSION}

This chapter has presented the design and implementation of an application prototype that permits teachers and course developers manage and share open assessment resources in an easy way. The development of the prototype also helped to prove that an application could connect and interact easily with a federated repository of educational resources, the Open ICOPER Content Space, through the use of the middle layer API.

The implemented prototype also satisfies the requirements established by the use cases, so it is supposed to fulfil stakeholders' requirements in the assessment process.

On the basis of the experience gained from the development of this prototype, a series of recommendations for the management of open assessment resources in a repository have been presented. These recommendations are related to the idea of extending the IMS QTI specification in order to link it to other e-learning fields. This integration brings some benefits, which emerge in the context of e-learning material repositories with several types of content, i.e., learner assessments, learning designs, learning outcomes, teaching and assessment methods, etc.

There are also other important concepts related to the recommendations, like the need of hiding the complexity of the specifications to the faculty members, and the great benefits of using formative assessment and tools that enable this practice. 


\section{ACKNOWLEDGMENT}

This work was partially funded by the Best Practice Network ICOPER (Grant No. ECP-2007EDU-417007), the Learn3 project, "Plan Nacional de I+D+I" TIN2008-05163/TSI, and the eMadrid network, S2009/TIC-1650, "Investigación y Desarrollo de tecnologías para el e-learning en la Comunidad de Madrid"

\section{REFERENCES}

Agea, Á., Crespo, R. M., Delgado Kloos, C., Gutiérrez, I., Leony, D., \& Pardo, A. (2009). Analysis of existing specifications and standards for assessment and evaluation and their usage in Europe. ICOPER D6.1, (pp. 1-103).

Agea, Á., Crespo, R. M., Delgado Kloos, C., Gutiérrez, I., Leony, D., \& Pardo, A. (2010). Production flow description and prototype for the two platforms under study (Moodle and. LRN) including the required steps to exchange the material in both platforms. ICOPER D6.2, (pp. 1-45).

Bloom, B. S., Hastings, J. T., \& Madaus, G. F. (1971). Handbook on formative and summative evaluation of student learning. New York, NY: McGraw-Hill.

Crespo, R. M., Najjar, J., Derntl, M., Leony, D., Neumann, S., Oberhuemer, P., et al. (2010). Aligning assessment with learning outcomes in outcome-based education. EDUCON 2010: IEEE Annual Global Engineering Education Conference, 14-16 April 2010, Madrid, Spain.

Fetlar project. (2010). End-to-end e-assessment with the FETLAR technical outputs. Retrieved October 2010, from http://www.fetlar.bham.ac.uk/

Gutiérrez Rojas, I., Agea, Á., Crespo, R. M., Pardo, A., \& Delgado Kloos, C. (2009). Assessment Interoperability using QTI. Interactive Conference on Computer Aided Learning.
Gutiérrez Rojas, I., Leony, D., Crespo, R. M., Pardo, A., Delgado Kloos, C., \& Franco, A. (2010). Management of assessmentresources in a federated repository of educational resources. In M. Wolpers, P. A. Kirschner, M. Scheffel, S. Lindstädt, \& V. Dimitrova (Eds.), EC-TEL 2010: Sustaining TEL: From innovation to learning and practice, Barcelona, Spain, 29 Sept.-1 Oct. 2010. Springer.

ICOPER. (2010). Project website. Retrieved October 2010, from http://icoper.org

IMS. (2010). Common cartridge (CC). Retrieved October 2010, from http://www.imsglobal.org/cc/

IMS. (2010). Question \& test interoperability (QTI) specification. Retrieved October 2010, from http://www.imsglobal.org/question/

JISC. (2010). UK OER program. Retrieved October 2010, from http://www.jisc.ac.uk/oer

JorumOpen.(2010). Learning to share. Retrieved October 2010, from http://open.jorum.ac.uk/xmlui

Klerkx, J., Vandeputte, B., Parra, G., Santos, J. L., Van Assche, F., \& Duval, E. (2010). How to share andreuselearning resources: The ARIADNE experience. European Conference on Technology Enhanced Learning (ECTEL 2010)

Najjar, J., Derntl, M., Klobučar, T., Simon, B., Totschnig, M., Grant, S., \& Pawlowski, J. (2010). A data model for describing and exchanging personal achieved learning outcomes (PALO). International Journal of IT Standards and Standardization Research, 8(2), 2010. doi:10.4018/ jitsr.2010070107

Quality Assurance Agency for Higher Education (QAA). (2000). Code of practice for the assurance of academic quality and standards in higher education, Section 6: Assessment of students. Retrieved October 2010, from http://www.qaa. ac.uk/academicinfrastructure/codeOfPractice/ section6/default.asp 
Totschnig, M., Derntl, M., Gutiérrez, I., Najjar, J., Klemke, R., Klerkx, J., et al. (2010). Repository services for outcome-based learning business. Barcelona, Spain: SE@M 2010.

Yorke, M. (2003). Formative assessment in higher education: Moves towards theory and the enhancement of pedagogic practice. Higher Education, 45, 477-501. doi:10.1023/A:1023967026413

\section{ADDITIONAL READING}

ABET. (2008). Accreditation policy and procedure manual.

Almond, R. G., Dibello, L., Jenkins, F., Senturk, D., Mislevy, R. J., Steinberg, L. S., \& Yan, D. (2001). Models for conditioning probability tables in educational assessment. Artificial intelligence in Statistics Conference, 2001

APIS QTIv2.(n.d.). Assessmentengine. Retrieved September 2010 from http://sourceforge.net/ projects/apis/

Bangert-Drowns, R. L., Kulick, J. A., \& Morgan, M. T. (1991). The instructional effect of feedback in test-like events. Review of Educational Research, 61(2), 213-238.

Barrett, H. C. (2001). Electronic portfolios. In Educational technology: An encyclopedia. ABCCLIO.

Biggs, J. B. (2003). Teaching for quality learning at university.

Black, P., \& Wiliam, D. (1998). Assessment and classroom learning. Assessment in Education, 5(1), 7-74. doi:10.1080/0969595980050102

Black, P., \& Wiliam, D. (1998). Inside the black box: Raising standards through classroom assessment. Phi Delta Kappan, 80(2), 139-148.
Blat, J., Navarrete, T., Moghnieh, A., \& BatlleDelgado, H. (2007). A QTI management system for service oriented architectures. Proceedings of the TENCompetence Open Workshop on Service Oriented Approaches and Lifelong Competence Development Infrastructures, Manchester, UK, (pp. 175-181).

Boston, C. (2002). The concept of formative assessment. Practical Assessment, Research \& Evaluation, 8(9). Retrieved September 2010 from http://PAREonline.net/getvn. asp? $\mathrm{v}=8 \& \mathrm{n}=9$

Boud, D., \& Falchikov, N. (1989). Quantitative studies of student self-assessment in higher education: A critical analysis of findings. Higher Education, 18, 529-549. doi:10.1007/BF00138746

Conole, G., \& Warburton, B. (2005). A review of computer-assisted assessment. ALT-J Research in Learning Technology, 13, 17-31. doi:10.1080/0968776042000339772

De Finetti, B. (1965). Methods of discriminating levels of partial knowledge concerning a test item. The British Journal of Mathematical and Statistical Psychology, 18, 87-123. doi:10.1111/j.2044-8317.1965.tb00695.x

Dianne, C. (2008). Situating prior learning assessment and recognition (PLAR) in an online learning environment. In T. Anderson (Ed.), The theory and practice of online learning, 2 nd ed. AU Press, Athabasca University.

Dochy, F. J. R. C., \& McDowell, L. (1997). Assessment as a tool for learning. Studies in Educational Evaluation, 23, 279-298. doi:10.1016/ S0191-491X(97)86211-6

Elawar, M. C., \& Corno, L. (1985). A factorial experiment in teachers' written feedback on student homework: Changing teacher behaviour a little rather than alot. Journal of Educational Psychology, 77(2), 162-173. doi:10.1037/0022-0663.77.2.162 
European Qualifications Frameworkfor Lifelong Learning (EQF). (20080. Falchikov, N., \& Boud, D. (1989). Student self-assessment in higher education: A meta-analysis. Review of Educational Research, 59, 395-430.

Fantuzzo, J. W., Dimeff, L.A., \& Fox, S. L. (1998). Reciprocal peer tutoring: a multimodal assessment of effectiveness with college students. Teaching of Psychology, 16(3).

Fettke, P., \& Loos, P. (2003). Classification of reference models - A methodology and its application. Journal of Information Systems and e-Bussiness Management, 1, 3-53.

Fettke,P., \& Loos, P.(2006). Using referencemodels for business engineering-State-of-the-art and future developments, innovations in Information Technology (pp. 1-5). IEEE Computer Society Press.

Fontana, D., \& Fernandes, M. (1994). Improvements in mathematics performance as a consequence of self assessment in Portuguese primary school pupils. The British Journal of Educational Psychology, 64(3), 407-417. doi:10.1111/j.2044-8279.1994.tb01112.x

Frederiksen, J.R., \& White, B. J.(1997). Reflectiveassessment of students'research within an inquiry-based middle school science curriculum. Paper presented at the annual meeting of the American Educational Research Association, Chicago, IL, USA, 1997.

Freeman, R., \& Lewis, R. (1998). Planning and implementing assessment. Kogan Page.

FREMA Project. (2006). Retrieved from http:// www.frema.ecs.soton.ac.uk/

FREMAReference Model.(2007). Retrieved from http://wiki.frema.ecs.soton.ac.uk/

Gamma, E., Helm, R., Johnson, R., \& Vlissides, J. (1995). Design patterns: Elements of reusable object-oriented software. Boston, MA: AddisonWesley.
Gutiérrez, I., Crespo, R. M., Leony, D., \& Delgado Kloos, C. (2011). D6.3 -ISURE Best practice guidelines for assessment and evaluation specifications and standards. ICOPER D6.3, 1-120.

Harlen, W. (2005). Teachers' summative practices and assessment for learning - Tensions and synergies. Curriculum Journal, 16(2), 207-223. doi:10.1080/09585170500136093

Ibáñez, M. B., Crespo, R. M., \& Delgado Kloos, C. (2010). Assessment of knowledge and competencies in 3D virtual worlds: A proposal. In IFIP TC 3 International Conference, KCKS 2010. Held as part of WCC2010 (Brisbane, Australia, 2010), Springer, (pp. 165-176).

JISC: Methods of Assessment. (n.d.). Retrieved from http://www.bisinfonet.ac.uk/InfoKits/ effective-use-of-VLEs/e-assessment/assessmethods

Keller, G., \& Teufel, T. (1998). SAP R/3 process oriented implementation - Iterative process prototyping. Harlow, MA: Addison-Wesley.

Loll, F., \& Pinkwart, N. (2009). Using collaborative filtering algorithms as elearning tools. 42th Hawaii International Conference on System Sciences, 2009 (HICSS'09).

Morillo Arroyo, D., Santos Rodríguez, P., Pérez Calle, D., Delgado Kloos, C., Ibáñez Espiga, M. B., \& Hernández-Leo, D. (2010). Assessment in 3D virtual worlds: QTI in wonderland. Proceedings of Congreso Iberoamericano de Informática Educativa 2010, Volume I.

Muñoz-Merino, P. J., \& Delgado Kloos, C. (2009). A software player for providing hints in problembased learning according to a new specification. Computer Applications in Engineering Education, 17(3), 272-284. doi:10.1002/cae.20240 
Muñoz-Merino, P. J., Delgado Kloos, C., \& Muñoz-Organero, M. (2010). Enhancement of student learning through the use of a hinting computer e-learning system and comparison with human teachers. IEEE Transactions on Education.

Muñoz-Merino, P. J., Delgado Kloos, C., \& Muñoz-Organero, M. (2010). Behavior effect of hint selection penalties and availability in an intelligent tutoring system. International Tutoring Systems Conference, Pittsburg, United States.

Muñoz-Merino, P. J., Delgado Kloos, C., \& Muñoz-Organero, M. (2011). Deciding on different hinting techniques in assessments for intelligent tutoring systems. International Journal of Innovative Computing Information and Control, 7(1).

Muñoz-Merino, P. J., Delgado Kloos, C., MuñozOrganero, M., \& Fernández-Naranjo, J. (2008). Design and data analysis of exercises with hints. F2B-15-F2B-20. ASEE/IEEE Frontiers in Education Conference, Saratoga Springs, New York, United States.

Neumann, G., \& Erol, S. (2008). From a social wiki to a social workflow system. In D. Ardegna, M. Mecella \& J. Yang, (Eds.), Business Process Management Workshops 2008 LNBIP 17, (pp. 698-708). Milan, Italy, September 2008. Springer.

Radenkovic, S., Krdzavak, N., \& Devedzik, V. (2007). A QTI metamodel. Proceedings of the International Multiconference on Computer Science and Information Technology.

Ramaprasad, A. (1983). On the definition of feedback. Behavioral Science, 28(1), 4-13. doi:10.1002/bs.3830280103
Reed, D. (2006). Diagnostic assessment in language teaching and learning. Center for Language Education and Research, 10(2). Retrieved from http://clear.msu.edu/clear/newsletter/files/ fall2006.pdf

Sadler, D. R. (1989). Formative assessment and the design of instructional systems. Instructional Science, 18(2), 119-144. doi:10.1007/ BF00117714

Sluijsmans, D. M. A., Brand-Gruwel, S., van Merriënboer, J. J. G., \& Martens, R. L. (2004). Training teachers in peer-assessment skills: Effects on performance and perceptions. Innovations in Education and Teaching International, 4l(1).

TenCompetence Project. (2010). Retrieved September 2010 from http://www.tencompetence. org/

Topping, K. (1998). Peer assessment between students in colleges and universities. Review of Educational Research, 68(3), 249-276.

Vogten, H., Martens, H., Nadolski, R., Tattersall, C., van Rosmalen, P., \& Koper, R. (2006). CopperCore service integration - Integrating IMS learning design and IMS question and test interoperability. Sixth IEEE International Conference on Advanced Learning Technologies (ICALT'06).

Wills, G., Bailey, C., Davis, H., Gilbert, L., Howard, Y., Jeyes, S., et al. (2007). An e-learning framework for assessment (FREMA). In Proceedings for 11th CAA Conference 2007.

Yorke, M. (2003). Formative assessment in higher education: Moves towards theory and the enhancement of pedagogic practice. Higher Education, 45, 477-501. doi:10.1023/A:1023967026413 


\section{KEY TERMS AND DEFINITIONS}

.LRN Platform: .LRN is the world's most widely adopted enterprise-class open source software for supporting e-learning and digital communities. Originally developed at MIT, .LRN is used worldwide by over half a million users in higher education, government, non-profit, and K-12.

Interoperability: is a property referring to the ability of diverse systems and organizations to work together (inter-operate). The term is often used in a technical systems engineering sense, or alternatively in a broad sense, taking into account social, political, and organizational factors that impact system to system performance.

Learning Design: A learning design is a reusable representation of a concrete learning opportunity. A learning design arranges teaching methods, assessment designs, learning content and other elements of a learning environment such as learning tools towards learning outcome attainment.

Learning Outcome: means statements of what a learner knows, understands and is able to do on completion of a learning process. It covers knowledge, skills and competences that a learner should attain when successfully having finished a unit of learning.

OICS: In the context of the ICOPER project, the Open ICOPER Content Space has been defined as the umbrella combining a portfolio of interoperable repositories, content and tools, as a test bed for the specifications and standards that become part of the ICOPER reference model.

Open Repository of Educational Resources: is a collection of open educational resources (resources used in education) that can be accessed to retrieve information. Repositories often consist of several databases tied together by a common search engine.

Outcome-Based Assessment: means that the assessment process must be aligned with the learning outcomes. This means that it should support the learners in their progress (formative assessment) and validate the achievement of the intended learning outcomes at the end of the process (summative assessment). It also means that the assessment process should be adapted depending on the kind of outcomes that it is aimed to appraise.

Standards and Specifications: Aspecification is an explicit set of requirements to be satisfied by a material, product, or service. A technical specification may be developed privately, for example by a corporation, regulatory body, or military organisation, or it may be developed by standards organizations. When a specification is issued by a standardisation body, it becomes a standard. 